\title{
Task Modification and Knowledge Utilization by Korean Prospective Mathematics Teachers
}

\author{
Kyeong-Hwa Lee ${ }^{1 *}$, Eun-Jung Lee ${ }^{1}$, Min-Sun Park ${ }^{1}$
}

${ }^{1}$ Seoul National University, Korea
*Corresponding Author: khmath@snu.ac.kr

Citation: S Lee, H. K. , Lee J. E. \& Seah T. (2016) Task Modification and Knowledge Utilization by Korean Prospective Mathematics Teachers, Pedagogical Research, 1:2 (2016), 54.

doi:http://dx.doi.org/10.20897/lectito.201654

Published: November 15, 2016

\section{ABSTRACT}

It has been asserted that mathematical tasks play a critical role in the teaching and learning of mathematics. Modification of tasks included in intended curriculum materials, such as textbooks, can be an effective activity for prospective teachers to understand the role of mathematical tasks in the teaching and learning of mathematics; designing of new tasks requires more knowledge and experience. This study aims to identify the patterns that Korean prospective mathematics teachers seem to follow when they modify the mathematical tasks in textbooks. Knowledge utilized by prospective teachers while they modify textbook tasks is identified and characterized in order to understand the possible factors that have an impact on Korean prospective mathematics teachers' modification of tasks.

Keywords: prospective teachers, task modification, teacher knowledge

\section{INTRODUCTION}

It is mentioned in many previous studies that mathematical tasks play a critical role in the teaching and learning of mathematics. In fact, some studies (for example, Kaur \& Yeap, 2009; Krulik \& Rudnick, 1999; Prestage \& Perks, 2007; Thompson, 2012) analyzed learning opportunities that tasks provide according to task types, and some other studies (for example, Kullberg, 2010, 2012; Sullivan, 2003, 2009) explored the relationship between tasks and teaching and learning. As it has been claimed that tasks are important to link teaching to learning of mathematics, some studies on teacher education point out that teacher professional development programs are needed to analyze tasks in terms of learning opportunities and design instructional tasks accordingly.

It has been asserted that mathematical tasks play a critical role in the teaching and learning of mathematics (Crespo, 2003; Henningsen \& Stein, 1997; Stein, Grover, \& Henningsen, 1996; Watson \& Mason, 2007). Henningsen and Stein (1997), for example, pointed out that tasks with different natures may provide different opportunities to develop students' mathematical thinking and reasoning skills. Furthermore, they argued that teachers' goals, mathematical knowledge, and knowledge of students can influence how the teachers set up the tasks included in intended curriculum materials, such as textbooks. This indicates that students' mathematics learning can be positively influenced by tasks that teachers modify or develop through their content and pedagogical knowledge. Therefore, the issue of teachers' competency to modify and pose meaningful tasks needs to be addressed more actively in teacher education. However, according to Watson and Mason (2007), who reviewed the submitted proposals for the special issue of the Journal of Mathematics Teacher Education, only a few papers dealt with issues in teachers' critical analyses such as task analysis, task evaluation, or posing tasks. This tendency is in line with the comment by Prestage and Perks (2007), which is that the issue of how teachers pose and organize tasks to educate students in classrooms has been ignored. 
A teacher's ability to analyze and modify tasks to be used in the classroom or pose worthwhile tasks may be a critical factor affecting students' mathematics learning. However, such skills cannot be developed in just a short time, so teachers need continuing and systematic support to develop these skills (Crespo, 2003; Prestage \& Perks, 2007).

In Korea, since about $90 \%$ of secondary mathematics teachers, tend to use textbooks as a major resource in classrooms (Mullis, Martin, Gonzalez, \& Chrostowski, 2004), it seems especially important for prospective teachers to have opportunities to perform critical analyses and modifications of the tasks provided in textbooks. The purpose of this study is to identify the patterns that Korean prospective mathematics teachers tend to follow when they modify mathematical tasks in textbooks. Knowledge utilized by prospective teachers while they modify textbook tasks is identified and characterized to understand the possible factors that have an impact on Korean prospective mathematics teachers' modification of tasks.

\section{Theoretical background}

\section{Mathematics tasks and teaching-learning}

Tasks can be designed in different forms according to the objective and orientation, and every single task form provides a different learning opportunity for students. Prestage and Perks (2007) suggested that transforming only the conditions of closed problems in school textbooks by adding or deleting conditions can foster students' mathematical thinking. When conditions in problems are deleted, students can add specific conditions according to their own idea. When conditions are added, students can have chances to extend their scope of knowledge through problem- solving. Thompson (2012) attempted the transformation of textbook exercises according to the following strategies to reflect the new curriculum's point of view, which emphasizes both reasoning and communication: a) to reframe a basic problem by including one or more conditions, b) to use relationships to find patterns or predict other results, c) to generate conjectures for students to investigate, d) to encourage students to solve a problem in multiple ways, e) to evaluate student solutions, f) to write a question appropriate for a given answer, and g) to connect procedural and conceptual knowledge. The different learning opportunities from each task can be identified when tasks in textbooks are modified to require high cognitive demand (Kaur \& Yeap, 2009) or to develop critical thinking and creativity (Krulik \& Rudnick, 1999).

Competency in task design has been taken into consideration in mathematics teacher education. Crespo (2003), who studied problem posing by prospective teachers, found that prospective teachers' problem posing skills had changed from posing single steps and computational problems to posing problems requiring multiple solutions and approaches, and open-ended and exploratory problems. She also reported that in the beginning of the study the participants paid more attention to students' motivation and posed simple problems, but their attention later shifted to students' misconceptions, so they posed problems that were more challenging and had higher cognitive demands. This study seems meaningful in that it showed prospective teachers' problem posing competency could improve through experience in making problems and providing them to students, but the study lacks an analysis of prospective teachers' intentions in the problems they pose as well as student learning opportunities provided by these problems.

Stein and Lane (1996) pointed out the necessity of studying the linkage between mathematics teaching, learning, and instructional tasks and suggested a conceptual framework to explore the relationship between them. Some later studies have tried to explore the relationship between teaching, learning, and tasks more systematically, and those studies argued that teachers needed to develop their competency for task analysis and design.

Zaslavsky (2008) showed changes in the teaching and learning of mathematics after task modification. Analyzing different versions of tasks promotes teachers' development of adaptability; fosters their awareness of similarities and differences; helps them learn how to cope with conflicts, dilemmas, and problem situations; encourages them to learn from the study of practice; teaches them to select and use appropriate tools and resources for teaching; helps them to identify and overcome barriers to students' learning; and allows them to share and reveal self, peer, and student dispositions. She claims that teachers can foster their professionalism after analyzing the tasks. The finding from this study, showing that mathematics teaching and learning became changed by being aware of student learning opportunities in the process of analyzing and modifying the tasks, can support the claim by Holmqvist, Brante, and Tullgren (2012) that it is difficult to understand students' thinking by only observation without making any plan to analyze it.

Other attempts to link between tasks, teaching, and learning are the studies by Kullberg and Sullivan. Studies by Kullberg $(2010,2012)$ and Kullberg, Runesson, and Martensson (2013) were based on variation theory developed by Marton and Tsui (2004), in which, learning is considered 'discerning specific features of an object of learning (Kullberg, 2012, p 169).' According to this view on learning, Kullberg and her colleagues claimed that it 
was possible to help students experience variation and invariance related to critical features for student learning via task and lesson design including variation and invariance. Kullberg (2010) tried to make a connection between what is taught and what is learned using intended task design. She showed, for example, that if addition and subtraction of negative numbers are a learning object, one of the critical features for learning the object is the minus sign can be used either to show subtraction or a negative number. To discern the critical feature, the dimension of variation is "subtraction" and "negative number," and tasks using variation and invariance should be designed to give students opportunities to discern the difference between a subtraction sign and a negative number sign. In fact, Kullberg and her colleagues (Kullberg et al., 2013) found empirical evidence in their studies showing that tasks designed by variation theory affect student learning. Those studies are meaningful in that the studies systematically show that different opportunities to learn mathematical concepts can be given to students by using a variation of tasks.

Kullberg et al. (2013) also claims the importance of implementation of tasks in mathematics lessons. She showed that although different teachers may use the same task, different ways in which they implement the task in their classrooms can significantly affect their students' learning, and asserted that teachers need to be aware of the importance of task implementation. This study's finding is in line with Stein and Lane's study (1996), which showed that interactions between teachers and their students might change the nature and cognitive demand of intended tasks during their implementation in lessons. These two studies indicate that teachers need experience to analyze the potential learning opportunities that tasks have and consider how to implement tasks effectively.

As Kullberg and her colleagues studied, Watson and Mason (2005) also used the term "dimensions of possible variation", which is one of the important components of variation theory. They asserted that teachers can promote students' natural inquiry abilities by helping their students generate and expand their example spaces via tasks designed in terms of dimensions of possible variation and ranges of change. Watson and Mason supported their assertion about the importance of example spaces, showing various tasks with dimension of variation and range of permissible change and learners' expected responses on those tasks. They also mentioned the need for discussion of pedagogical issues such as what sequences or types of tasks are provided and what questions are asked to encourage learners to generate their example spaces (Watson \& Mason, 2005; Watson, 2007; Watson, 2004). Both studies by Kullberg and her colleagues and Watson and Mason, with the assumption that learning can take place only if students discern invariant and variant features of learning objects, suggest that teachers can anticipate students' various responses and prepare for appropriate actions to promote student learning via systematic designing of tasks and lessons.

Sullivan and Mousley (2001) noted that when teachers use more open-ended and inquiry-based tasks in their mathematics classes to provide students with opportunities to construct mathematical knowledge by themselves, teachers spend less time on direct explanation of mathematical concepts than teachers in traditional mathematics classrooms, but need to make more decisions. In other words, teachers need to be active decision makers to connect learning opportunities that tasks potentially have to student learning, and teachers' decision making can play a critical role in the link between teaching and learning. Sullivan, in his later studies (Sullivan, 2003; Sullivan, 2009; Sullivan, Griffioen, Gray \& Powers, 2009), used open-ended tasks for teachers' task analysis activities in teacher development programs. According to Sullivan and his colleagues, teachers could identify potential learning opportunities and constraints that open-ended tasks have via task analysis activities and could develop teacher knowledge that helps them plan their lessons by maximizing learning opportunities and minimizing constraints of tasks.

Sullivan, Clarke, Clarke, and O'Shea (2010) explored the relationship between tasks, teacher actions, and student learning. Three teachers participated in their study and taught their students using the same tasks. During their classes, the researchers analyzed the actions the teachers took to convert the tasks to learning opportunities for their students and investigated the effects of teachers' actions on potentials of the tasks, teachers' intentions, and student learning. The findings showed that two of the teachers who lacked confidence in their mathematical knowledge intentionally made the tasks simple and discouraged students' various methods of solutions, which consequently reduced the potentials of tasks that could promote student learning. Similarly, Sullivan, Clarke, and Clarke (2009) surveyed primary and secondary mathematics teachers to investigate how they use mathematics tasks in their classes. The researchers found that many teachers had difficulties in using tasks in their lessons properly and argued that teachers needed teacher knowledge such as common content knowledge, specialized content knowledge, and pedagogical content knowledge to convert tasks to learning opportunities. Sullivan and his colleagues' studies indicate that teachers may be challenged by the translation of tasks into appropriate learning opportunities for students, and therefore they should be supported by teacher development programs to design mathematics tasks and convert tasks into a lesson. Voica and Pelczer (2009) investigated the difference between prospective teachers' and in-service teachers' design of problem posing tasks. In- service teachers considered the

(C) 2016 by author/s 
students, reflected the curriculum, and applied their pedagogical knowledge and mathematical knowledge, whereas prospective teachers mostly focused on the context without considering the students or the level of difficulty. Differences between in-service and prospective teachers are typically caused by differences in teacher knowledge.

\section{Teacher knowledge}

Ball and her colleagues proposed Mathematical Knowledge for Teaching (MKT) based on Shulman's categories of teacher knowledge (Ball, Thames, \& Phelps, 2008; Hill, Ball, \& Schilling, 2008). According to them, MKT is categorized into two main domains: Subject Matter Knowledge (SMK) and Pedagogical Content Knowledge (PCK). SMK is subdivided into three categories: Common Content Knowledge (CCK), Specialized Content Knowledge (SCK), and Horizon Content Knowledge (HCK). PCK is also subdivided into three categories: Knowledge of Content and Students (KCS), Knowledge of Content and Teaching (KCT), and Knowledge of Content and Curriculum (KCC). A brief explanation about some constituents of MKT follows (see Ball et al. (2008) and Hill et al. (2008) for more details). CCK, which is included in SMK, is defined as mathematical knowledge regardless of teaching, whereas SCK is mathematical knowledge and skill for teaching. To distinguish mathematical knowledge for teaching from mathematical knowledge, SMK was conceptualized by Ball and her colleagues, who emphasized the importance of SMK. KCS, which is included in PCK, is the combination of knowledge about students and knowledge about mathematics; for example, teachers with KCS can identify and predict the common errors that students are more likely to commit as well as their misconceptions. Finally, KCT is defined as the combination of knowledge about teaching and knowledge about mathematics. Teachers who possess KCT can identify appropriate examples they should first use to help students understand mathematical concepts or appropriate teaching sequences and methods for the design of instruction.

\section{METHOD}

Participants were 38 prospective secondary mathematics teachers who enrolled in the course, "A Study of Teaching Materials and Teaching Methods," taught by the first author of this paper. In the course, participants learnt about the Korean mathematics curriculum and teaching materials. At the end of this course, they were asked to analyze the tasks presented in the introduction of each unit of the secondary textbooks and modify them. The selection of tasks and the direction of modification were left up to the prospective teachers. Hence, they chose tasks from different units, such as function, geometry, algebra, or numbers; in particular, the function and geometry units were most frequently selected.

Most of the prospective teachers analyzed and modified more than two tasks, so all of the tasks that were done by each participant were analyzed in this study. In addition, the prospective teachers tended to use different types of teacher knowledge simultaneously in the processes of task analysis and modification, so all of those types of teacher knowledge were counted in the data analysis.

In this study, the task modification of prospective teachers was classified into three types: context modification, condition modification, and question modification. Context modification refers to modification by changing the context of tasks, making them student-friendly or diverse. Condition modification refers to modification by adding, deleting, or transforming the conditions in tasks (Prestage \& Perks, 2007). It can be related to the "what-if-not" strategies of Brown and Walter (1990), who mentioned the manipulation of the conditions of a problem when posing a new problem. Question modification refers to modification by changing what students are required to answer. We can find an example of question modification in Crespo (2003), who suggested changing the task into a more open-form or one that requires a process of investigation.

The authors of this study classified the modified tasks presented by the prospective teachers into types, and the classifications not agreed on by all of the authors were discussed until we reached an agreement. In addition, this study analyzed the types of teacher knowledge that the prospective teachers used for the task analysis and modification, according to the classification of teacher knowledge suggested by Ball et al. (2008). The types of teacher knowledge used by the prospective teachers were also analyzed in the same way that the classification of the modified tasks was analyzed

\section{FINDINGS}

\section{Types of task modification}

As mentioned above, the modified tasks presented by the prospective teachers were analyzed by the following criteria: context modification, condition modification, and question modification. Some prospective teachers made only one of the three types of modifications for any given question, while others simultaneously changed two or all three. Figure 1 shows the frequency of the prospective teachers' modifications by type or types, showing all 
possible combinations of the three types of modifications. As can be seen in the figure, the conditions of a task were the most often modified by the prospective teachers.

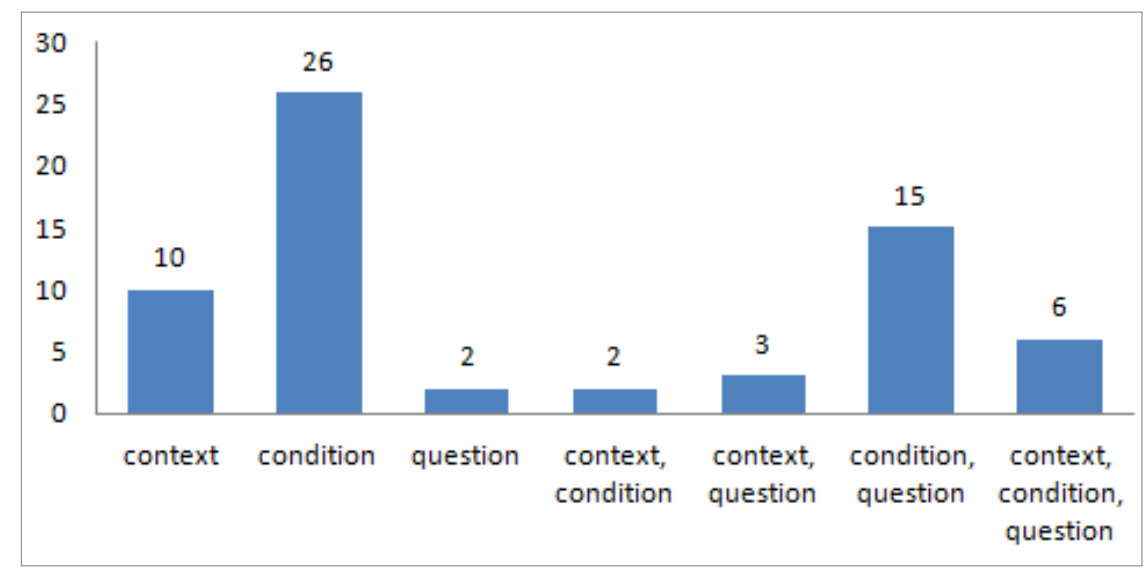

Figure :1 Quantity of prospective teachers' task modifications by type or all possible combinations of the three types of modifications

\section{Cases where only one type of task modification was made}

The number of tasks in which only the context was modified was 10 out of 64 , and in most of the cases, the context was changed to attract students' interests. The prospective teachers who performed context modification claimed that the contexts used in the tasks in the textbooks could not draw students' interest. Thus, they suggested that materials in which students were interested or contexts related to students' real life experiences should be used in tasks. For instance, Nam analyzed an existing task (Figure 2) involving the amount of water flowing from a tap. She thought this task was related to real life but could not engage students' interest. Thus, Nam changed the context to the use of electronic devices such as MP3 players that students often used. He considered that using an MP3 player as the context could induce students' interest and help them make the connection between mathematics and real life. He presented the modified context as follows:

A MP3 file of a song takes up 1 MB per minute. Jin wants to save the quantity $\mathrm{x}$ of his favorite threeminute songs in his MP3 player which has the capacity of y MB. Answer the following questions.

This example from tasks where the context was modified indicates that the Korean prospective teachers who participated in the study believed that contexts in mathematical tasks should be related to real life and also includes students' direct experiences. They tended to use context in a very limited view

How is a function applied in real life?
Let's think
Jin went to the restroom and saw that the tap
was not turned off. To investigate how much
water was wasted, he measured the amount of
flowing water for a minute and found out it was
2 L. Say $y$ is the amount of wasted water for $x$
minutes. Answer to the following questions.
(1) Seek the formula of $x$ and $y$.
(2) If water is flowing for 10 minutes, what is
the amount of wasted water?

Figure 2: An example of a task from a textbook used to introduce a real-life application of function

The number of tasks in which only the conditions were modified was 26 out of 64 . Most of the prospective teachers modified the conditions to correct misconceptions that students might have or to adjust the difficulty level of the tasks. Most prospective teachers who modified the conditions of the tasks to adjust the difficulty level tended to add graphs or pictures to help students' understanding of the tasks. Other prospective teachers noted 
that students might have misconceptions about mathematical ideas from the tasks in textbooks, so they modified the conditions of the tasks to prevent misconceptions. For example, Hee mentioned that the task in the introduction of the function unit (Figure 3) might cause some misconceptions. Hee was concerned that students might misunderstand that function as discrete, because the given domain of the task was not continuous, as it asked for each moving distance after 1 second, 2 seconds, 3 seconds, and 4 seconds. Thus, Hee modified the task by changing the condition to "show the graph of the distance the P-waves moved after 4 seconds." This modification focused only on preventing a misconception that might have made it difficult for students to perform a task given in the introduction of the unit.

In this study, tasks that prospective teachers were supposed to modify were presented in the introduction of each unit of the textbooks. Since the role of introduction is to give students motivation and interest, we expected that more of prospective teachers would modify the contexts rather than conditions or questions. However, prospective teachers modified the conditions most often, which showed that Korean prospective teachers are focusing on the main mathematical idea in tasks. Nevertheless, we need to be careful to determine whether they have modified conditions properly or not. When prospective teachers attempt to modify conditions, the main mathematical idea behind the task should be retained when adjusting the difficulty of the tasks. In the above example, Hee modified the conditions to prevent a misconception, but failed to adjust the difficulty. In addition, tasks can be made difficult by focusing on the main mathematical idea too much, which can cause vagueness or shift the focus of attention to tangential aspects of the main idea. This should be considered when prospective teachers want to modify the conditions of a task.

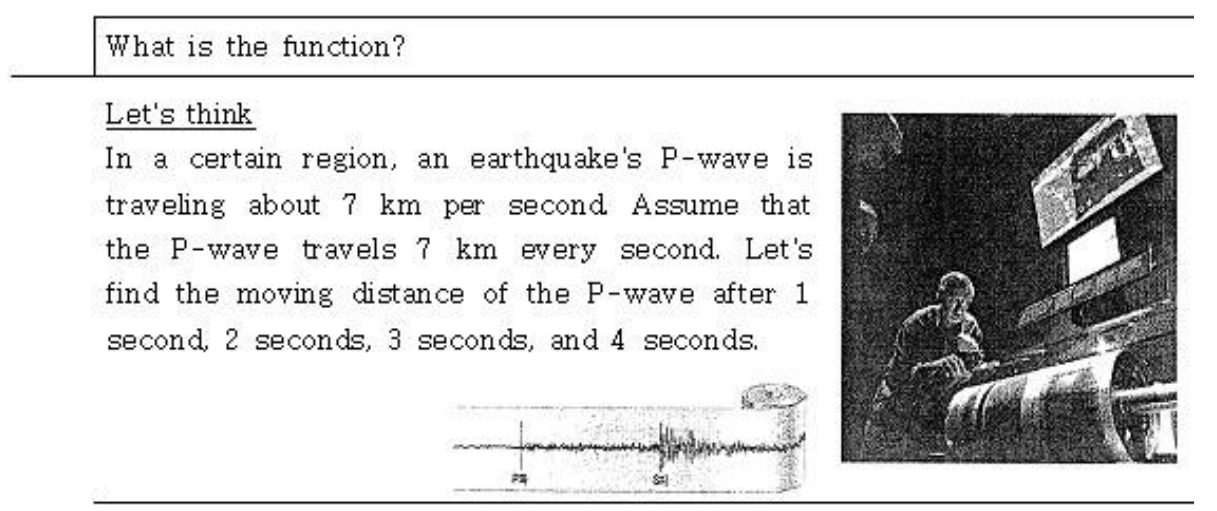

Figure 3: A task from a textbook used to introduce the concept of function

Finally, question was modified only twice out of sixty-four task modifications. The first was an instance where a question was added to connect what was learned with what will be learned. The prospective teacher mentioned that for the task in the introduction of the function application unit (Figure 2), question of drawing a graph which had been learned in a previous section should be added. He added a question as "(3) let's draw a graph and see the tendency of change." The second was where the existing question was added to require reasons for the answer. The prospective teacher changed the problem from "Compare each distance from O to three vertices" to "Compare each distance and give reasons for your answer." Even though two question modifications were presented, when prospective teachers made a question modification, they tended to modify conditions or context of tasks simultaneously rather than modifying question alone. Those cases are presented in the next section.

\section{Cases where multiple types of task modifications were made}

There were some prospective teachers who modified the task by focusing on more than one type of task modification. There are two cases where context and condition were modified, three cases where context and question were modified, fifteen cases where condition and question were modified, and six cases where all three types of modifications were made.

The number of cases in which the prospective teachers modified both context and condition at the same time was twice out of sixty-four. Sol modified the task from the introduction of the function unit (Figure 3). She considered that the task did not show arbitrariness and univalence, so it would lead to a misconception of the function. She thus modified the context by selecting material which shows the function concept properly and provides appropriate difficulty and interest to students, and added a condition by presenting one more new relation. By considering the condition and context at the same time, this prospective teacher presented a much richer and 
more meaningful task than prospective teachers who considered only the condition or context. Her modified task is given in Figure 4.

Prospective teachers modified both context and question at the same time in three times out of sixty-four cases. Jung modified the task from the introduction of congruence conditions of a right triangle in geometry (Figure 5, left). In the textbook, a picture of a sailboat with a red outline of a right triangle is presented. However, the question was not mention about the sailboat. Jung said that even though the important point is that a given triangle is a right triangle, it is just mentioned in a question and the question does not give students any opportunities to find the right triangle by themselves. Jung said that a sailboat is meaningful since it is one of mathematical phenomena showing a geometrical figure. However, it does not seem meaningful since the picture is not related to the activities which are applying or discovering phenomena. Jung presented the way of modification without changing or deleting the picture (Figure 5, right). She erased the red outline that given in the textbook, and make students find out geometrical figures from the picture and discover the properties of figures. It means that she changed the context from mathematical context to real-life context. Also, by leading to a discussion, she modified the question at the same time.

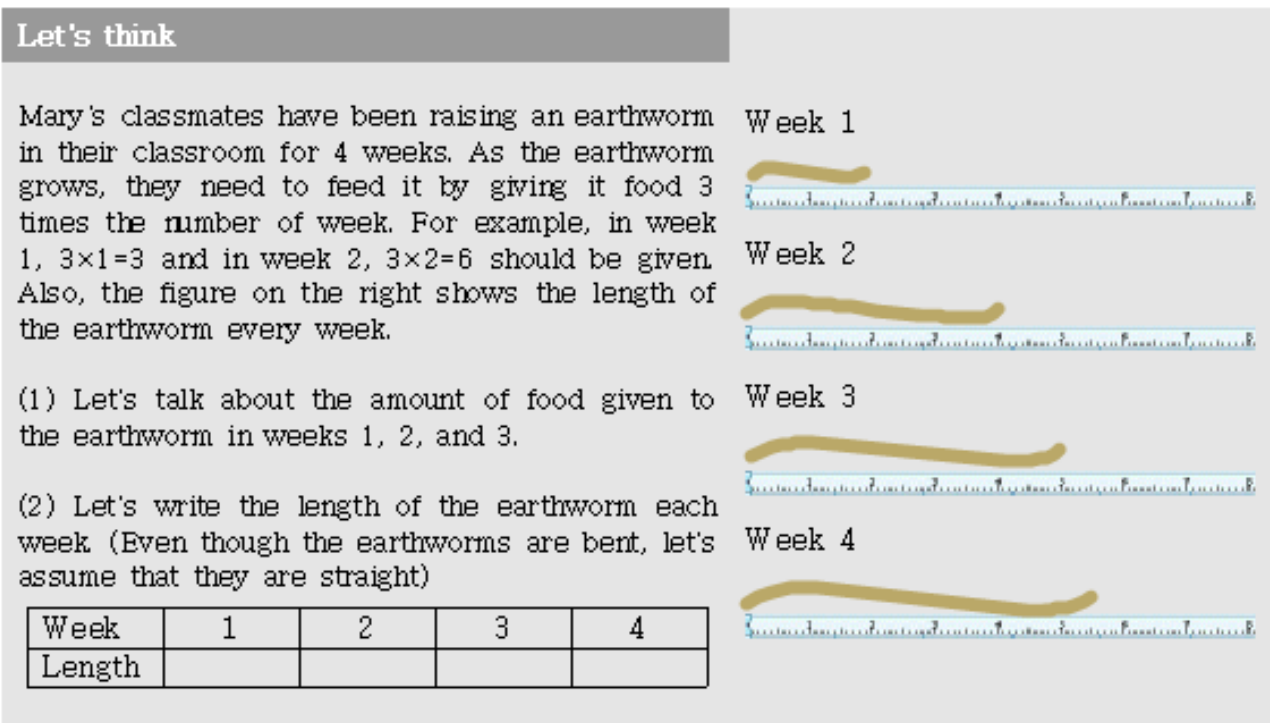

Figure 4: Sol's modification of the original task in Figure 3

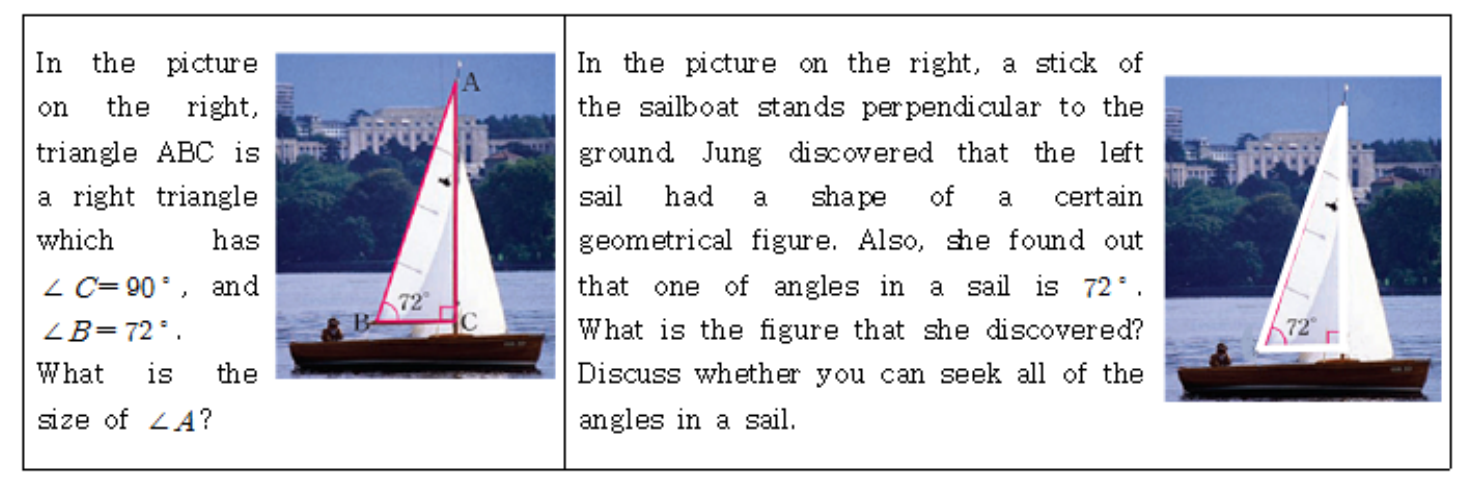

Figure 5: A task from a textbook designed to introduce congruence conditions of a right triangle. The original is on the left and Jung's modification is on the right

In 15 out of 64 cases, prospective teachers modified both the condition and question at the same time. Yun modified a task from the introduction of parallelogram conditions in geometry (Figure 6, left). In the textbook, Yun saw that this task gave students an opportunity to think about the reverse of a proposition that students already had learned. This task led to students to consider whether the reverse of proposition could be a condition for being a parallelogram. However, instead of stating propositions explicitly, giving students the opportunity to 
recall the properties of a parallelogram and to reason whether the reverse of a proposition can be a condition for being a parallelogram helps students learn the main mathematical idea effectively. By presenting open-ended questions instead of presenting properties explicitly, Yun modified the condition and question at the same time (Figure 6, right). He also added a new question which gave an opportunity for students to consider for whether the reverse of a proposition was true or false.

\begin{tabular}{|l|l|}
\hline $\begin{array}{l}\text { Let's talk about the reverse of the following } \\
\text { propositions: }\end{array}$ & $\begin{array}{l}\text { (1) Let's write one of the properties of the } \\
\text { parallelogram that you know. } \\
\text { IE In a parallelogram, }\end{array}$ \\
$\begin{array}{l}\text { (1) In a parallelogram, the lengths of both pairs } \\
\text { of opposite sides are the same. }\end{array}$ & (2) Let's write the reverse of (1). \\
$\begin{array}{l}\text { (2) In a parallelogram, both } \\
\text { pairs of opposite angles are } \\
\text { congruent. }\end{array}$ & IE \\
$\begin{array}{l}\text { (3) In a parallelogram, both } \\
\text { diagonals bisect each other. }\end{array}$ & (3) Let's think whether a proposition in (2) is \\
\end{tabular}

Figure 6: A task from a textbook designed to introduce the conditions of a parallelogram. The original is on the left and Yun's modified task is on the right

Chan also modified the both the condition and question at the same time. He modified a task designed to introduce isosceles triangles in geometry (Figure 7, left). He felt that the origami activity which was already being presented as an introductory task was appropriate to induce students' diagrammatic reasoning. However, to lead students to focus on the relationship between geometrical figures, he modified the questions to guide students' thinking. He suggested his idea as follows:

First of all, let's change the first question to "Find out the hidden triangles in triangle $A B C$, and mark them." This leads students to find and generate diagrams in triangle ABC. Since figures can be shown indirectly by folding the paper, this will not present any great difficulty. The figures that we expect students to find are two triangles that are congruent. At this point, students need to consider the relationship between the figures, so the second question should be, "Write down the similar properties of the two figures in (1)." Expected answers would not be limited to properties of angles. Instead, we expect them to observe all of the properties that the two triangles have. Listed properties would be related to the congruence conditions of the two triangles. Since students can easily see by folding the papers that the two figures overlap, they intuitively know that two figures are congruent in Euclidian Geometry. The final question would better be, "What properties does triangle ABC have?" This question leads students to see the two diagrams as one. These questions make students imagine appropriate images when they learn the proof subsequently.

Chan tried to modify the questions to help students focus on properties of the figure. Thus, he changed the condition to focus on properties the two figures had in common without specifically referring to the lengths of the sides or the measures of the angles. By modifying the question to make it a general, open-ended question about figures (Figure 7, right), Chan provides an opportunity for discovering propositions and allowing students to explore the figure, requiring deeper mathematical thinking.

Context, condition, and question were modified at the same time by prospective teachers in 6 out of 64 cases. Kim suggested that to introduce the use of letters to denote variables or constants in function, teachers need to focus on several aspects of the use of letters, especially, "letters used as a specific unknowns," "letters used as generalized numbers," and "letters used to simplify given situations in problems. Kim induced these aspects through the analysis of previous studies on the use of letters in mathematics curricula. Figure 8 shows a task used to introduce the use of letters given in a textbook. 


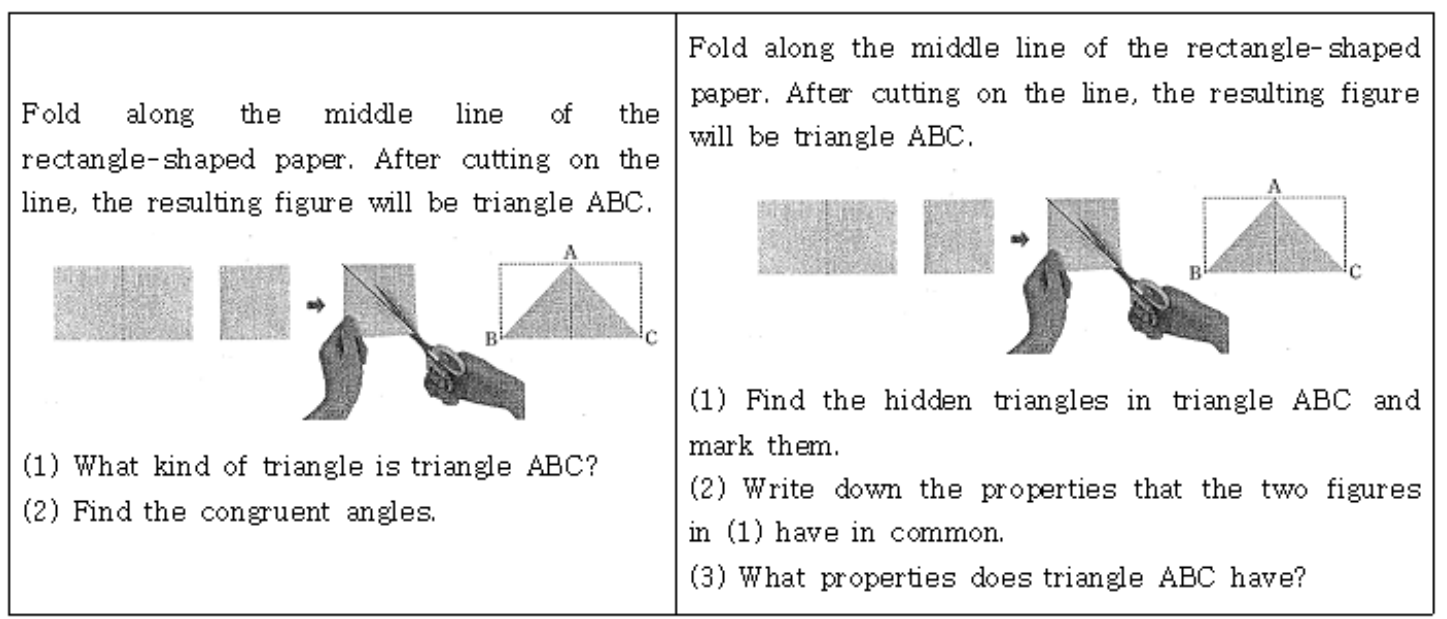

Figure 7: A task from a textbook designed to introduce properties of a triangle. The original task is on the left and Chan's modified task is on the right

How can we represent the formula using letters?
Let's think
A 10 -won coin which was issued by Korea Bank in
2006 was made by plating copper on aluminum. It
costs 6 won to make a 10 -won coin. Answer to the
following questions.
(1) How much does the cost increase when one more
10-won coin is made?
(2) How much does it cost to make 1010 -won coins?
(3) Represent the cost of making $\square 10$-won coins
using $\square$.

Figure 8: A task from a textbook designed to introduce use of letters in formulas

Among three aspects that Kim suggested, he asserted that this task should focus on "letters used as generalized numbers." However, since he believed that this task does not include the aspects of "letters used as specific unknowns" and "letters used to simplify given situations in problems," the task should be modified to include these aspects. In addition, Kim thought that the context of the task, the issuance of coins was not related to students' real life, so it does not cause students to be motivated or interested. Kim modified the task (Figure 9) to show how the process can be simplified by using letters. Also, to help students understand the meaning of simplification, he suggested the comparison and discussion of their answers as an activity. To reveal the aspect of "letters used as specific unknowns," he presented a question where students made formulas using specific numbers, and to reveal the aspect of "letters used as generalized numbers," he presented a question where students made formulas using words, signs, and letters. Kim claimed that the modified task not only revealed the three aspects that he had suggested, but also prevented students from having the following misconceptions about using letters: "considering the formula as incomplete if it contains operation signs" and "using the same letters to represent different values." In short, Kim modified the context so that it was more related to the students' lives. He modified the condition by changing the number of letters and by making several stages to show the simplifying process. 
Finally, he modified the question by presenting the comparison and discussion activity. He was able to present the task of introducing the use of letters by modifying the context, condition, and question at the same time.

Kim wanted to give his friends 500 -won pencils and 400-won erasers as gifts Some friends wanted pencils and others wanted erasers, so Kim surveyed his friends to determine who wanted a pencil and who wanted an eraser. He then determined the amount of money he needed.

\section{"The amount of money that I need is the sum of $\mathbf{5 0 0}$ won times the number or people who want pencils, 400 won times the number of people who want erasers, and 20 won, which is the cost of the paper bag."}

(1) If the number of people who want pencils is 4 and the number of people who want erasers is 5 , how can the cost be represented?

(2) Based on the formula from (1), let's simplify Kim's statement above using "the number of people who want pencils," "the number of people who want erasers," a plus sign, and a product sign.

(3) Let's simplify more the formula from (2) using letters (such as $\square, \Delta, 0,4$ ).

(4) Can you simplify more the formula from (3)? If possible, let's make it.

(5) Let's compare the formula from (4) with your teacher and classmates. Discuss which formula is the most simple while still preserving Kim's original meaning. Discuss the role of the use of letters in the formula.

Figure 9: Kim's modification of the original task presented in Figure 8

\section{Teacher knowledge}

As mentioned above, teacher knowledge can influence how teachers actually set up tasks in textbooks used in classrooms (Henningsen \& Stein, 1997). Similarly, when the prospective teachers modified tasks, teacher knowledge of content and pedagogy might affect the direction and process of modification.

We classified teacher knowledge according to what prospective teachers considered when they modified tasks. When prospective teachers considered the difficulty of the task or students' misconceptions or interest, they demonstrated KCS. When they focused on what example should be given or the way of teaching, they demonstrated KCT. KCC includes consideration of curriculum or the order of the mathematical content, and SCK includes the good usage of mathematical terms, mathematical ideas, mathematical history, and appropriate examples. CCK is related to general mathematical knowledge, and HCK is related to the relevance of the whole curriculum.

Figure 10 shows types of teacher knowledge used by the prospective teachers in the modification process. As can be seen in Figure 11, the prospective teachers used PCK more frequently than SMK; among PCK, KCS and KCT were more often used than the others. SCK among SMK was more frequently used than CCK and HCK. The SCK used by the prospective teachers was knowledge about mathematical ideas and their historical backgrounds, and various representations.

The fact that the prospective teachers used SCK more frequently than CCK indicates that they considered content knowledge to be more important for teaching than using only mathematical content knowledge for their modifications. SCK related to mathematical ideas seemed to have an impact on the identification of misconceptions that students might have, and the prospective teachers tried to modify tasks by suggesting teaching methods or procedures to prevent those misconceptions; in other words, SCK might affect KCS and KCT. The prospective teachers, furthermore, tried to modify tasks by applying the historic-genetic principle or asking 
students to present different representations on the basis of SCK related to historical backgrounds and various representations. From these findings, it can be clearly seen that content knowledge is closely related to pedagogical content knowledge.

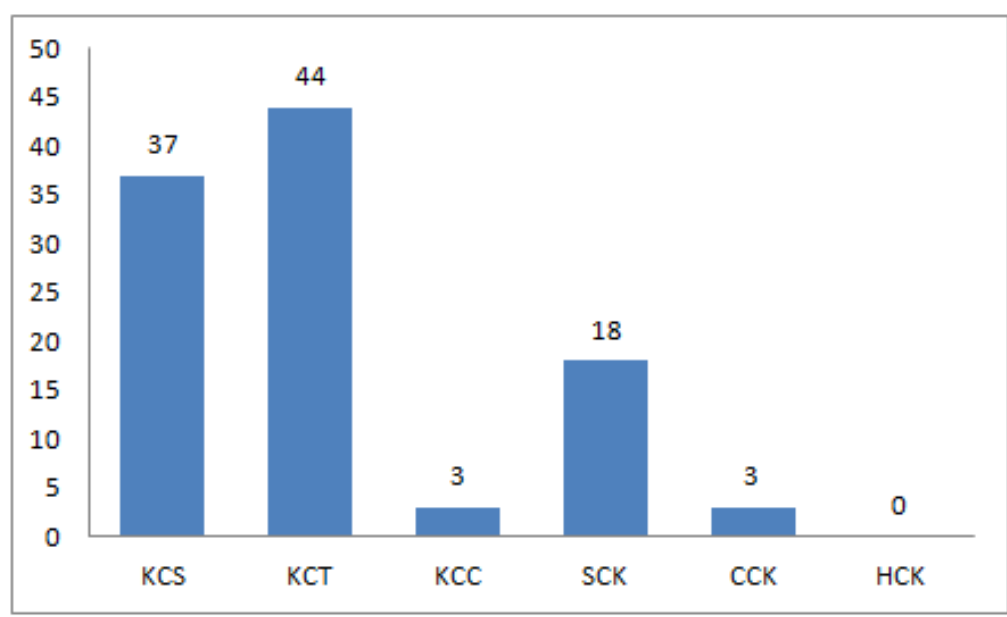

Figure 10: Frequency of use of type of teacher knowledge by prospective teachers in modification of tasks

\section{CONCLUSION}

In this study, we examined the types of task modification conducted by prospective teachers and the types of teacher knowledge that were activated during the modification process. By classifying the types of modification into context modification, condition modification, and question modification, we found that condition modification was performed at the highest rate. In addition, we found that when prospective teachers focused on two or more types of modification rather than focusing on only one, they modified the tasks in a more appropriate, richer, and more meaningful manner. KCT and KCS were the types of knowledge that prospective teachers used most frequently during modification, and they also used SCK at a high rate. However, other types of teacher knowledge were hardly displayed.

Prospective teachers were most likely to modify the conditions when they considered students' misconceptions and difficulty level, and intended to provide students with an opportunity to make a discovery. This result is consistent with the highest rate of the usage of KCT and KCS teacher knowledge types when prospective teachers modified the tasks. Also, because cognitive ability is necessary when modifying the conditions, prospective teachers' modification activated SCK as well.

Prospective teachers who used KCS as their type of teacher knowledge, especially those who considered students' interest, modified the context. Therefore, when they focused only on the context, they usually modified the context on a superficial level by presenting students with a familiar situation. When prospective teachers focused also on the condition or question along with context, they attempted to modify by using their KCS, especially the knowledge of misconceptions, and KCT. In this sense, prospective teachers who focused on more than two aspects at the same time were able to generate a more meaningful task because they activated various factors of teacher knowledge.

The number of prospective teachers who modified the context, conditions, and question all at the same time was not that high, surprisingly. To modify tasks in a meaningful way by considering all three factors, prospective teachers need not only KCT, KCS, and SCK but also need knowledge of the curriculum or the intent to relate the task to other mathematical concepts. Therefore, the reason that many prospective teachers did not consider all the aspects at the same time is that they possess narrow knowledge rather than balanced teacher knowledge.

\section{Contribution of this study to the field}

Teachers need to develop skills to design tasks to provide their students with opportunities to learn mathematics. However teachers' skills to design tasks cannot be developed in just a short time, so teachers need continuing and systematic support to develop these skills (Crespo, 2003; Prestage \& Perks, 2007). It may be challenging for prospective teachers to design new tasks because designing of new tasks requires more knowledge and experience. Therefore, modification of tasks included in textbooks can be an effective activity for prospective teachers to understand the role of mathematical tasks in mathematics teaching and learning, and also to identify 
their task modification patterns and their knowledge utilization can be helpful for teacher educators to develop teacher education programs to support teachers' task design.

\section{REFERENCES}

Ball, D., Thames, M., \& Phelps, G. (2008). Content knowledge for teaching: What makes it special? Journal of Teacher Education, 59, 389-407.

Brown, S. I., \& Walter, M. I. (1990). The Art of Problem Posing (2nd Ed.). Hillsdale, NJ: Lawrence Erlbaum Associates.

Crespo, S. (2003). Learning to pose mathematical problems: Exploring changes in preservice teachers' practices. Educational Studies in Mathematics, 52, 243- 270.

Henningsen, M., \& Stein, M. (1997). Mathematical tasks and students cognition: classroom-based factors that support and inhibit high-level mathematical thinking and reasoning. Journal for Research in Mathematics Education, 28, 524-549.

Hill, H., Ball, D., \& Schilling, S. (2008). Unpacking pedagogical content knowledge: Conceptualizing and measuring teachers' topic-specific knowledge of students. Journal for Research in Mathematics Education, 39, 372-400.

Holmqvist, M., Brante, G., \& Tullgren, C. (2012). Learning study in pre-school: Teachers' awareness of children's learning and what they actually learn. International Journal for Lesson and Learning Studies, 1, 153-167.

Kaur, B., \& Yeap, B. H. (2009). Pathways to Reasoning and Communication in the Secondary School Mathematics Classroom. Singapore: National Institute of Education.

Krulik, S., \& Rudnick, J. A. (1999). Innovative tasks to improve critical and creative thinking skills. In L. Stiff \& F. Curcio (Eds.), Developing Mathematical Reasoning in Grades K-12 (pp. 138-145). Reston, VA: National Council of Teachers of Mathematics.

Kullberg, A. (2010). What is taught and what is learned. Professional insights gained and shared by teachers of mathematics (Gothenburg studies in educational sciences 293). Göteborg: Acta Universitatis Gothoburgensis.

Kullberg, A. (2012). Students' open dimensions of variation. International Journal for Lesson and Learning Studies, 1, 168-181.

Kullberg, A., Runesson, U., \& Martensson, P. (2013). The same task? -different learning possibilities. In C. Margolinas (Ed.), Task Design in Mathematics Education: Proceedings of ICMI Study 22 (pp. 615-622). Retrieved from http:// hal.archives-ouvertes.fr/hal-00834054

Marton, F., \& Tsui, A. B. M. (2004). Classroom Discourse and the Space of Learning. Mahwah, NJ: Lawrence Erlbaum Associates.

Mullis, I., Martin, M., Gonzalez, E., \& Chrostowski, S. (2004). TIMSS 2003 International Mathematics Report: Findings from IEA's Trends in International Mathematics and Science Study at the Fourth and Eighth Grades.Chestnut Hill, MA: Boston College.

Park, K. M. (2004). Factors contributing to Korean students' high achievement in mathematics. In Korea subcommission of ICMI: The report on mathematics education in Korea (pp. 85-92). Seoul, Korea.

Prestage, S., \& Perks, P. (2007). Developing teacher knowledge using a tool for creating tasks for the classroom. Journal of Mathematics Teacher Education, 10, 381-390.

Stein, M. K., Grover, B., \& Henningsen, M. (1996). Building student capacity for mathematical thinking and reasoning: an analysis of mathematical tasks used in reform classrooms. American Educational Research Journal, 33, 455-488.

Stein, M. K., \& Lane, S. (1996). Instructional tasks and the development of student capacity to think and reason: An analysis of the relationship between teaching and learning in a reform mathematics project. Educational Research and Evaluation, 2(1), 50-80.

Sullivan, P. A. (2003). The potential of open-ended mathematics tasks for overcoming barriers to learning, In L. Bragg, C. Campbell, G. Herbert, \& J. Mousley (Eds.), Mathematics Education Research: Innovation, Networking, Opportunity: Proceedings of the 26th Annual Conference of the Mathematics Education Research Group of Australasia (pp. 813-816). Deakin University, Australia.

Sullivan, P. A. (2009). Constraints and opportunities when using content-specific open-ended tasks, In R. Hunter, B. Bicknell, \& T. Burgess (Eds.), Crossing divides: Proceedings of the 32nd Annual Conference of the Mathematics Education Research Group of Australasia (pp. 727-730). Palmerston North, New Zealand.

Sullivan, P. A., Clarke, D. M., \& Clarke, B. A. (2009). Converting mathematics tasks to learning opportunities: An important aspect of knowledge for mathematics teaching, Mathematics Education Research Journal, 21(1), 85105.

Sullivan, P. A., Clarke, D. M., Clarke, B. A., \& O'Shea, H. F. (2010). Exploring the relationship between tasks, teacher actions, and student learning, PNA, 4, 133-142.

Sullivan, P. A., Griffioen, M., Gray, H., \& Powers, C. (2009). Exploring open-ended tasks as teacher learning, Australian Primary Mathematics Classroom, 14(2), 4-9.

Sullivan, P. A., \& Mousley, J. (2001). Thinking teaching: seeing mathematics teachers as active decision makers. In F-L. Lin \& T. Cooney (Eds.), Making Sense of Mathematics Teacher Education (pp. 147-164). Dordrecht: Kluwer Academic Publishers.

Thompson, D. R. (2012). Modifying textbook exercises to incorporate reasoning and communication into the primary mathematics classroom. In B. Kaur, \& T. L. Toh (Eds.), Reasoning, Communication and Connections in Mathematics (pp. 57-74). Singapore: World Scientific Publishing Company.

Voica, C., \& Pelczer, I. (2009). Problem posing by novice and experts: Comparison between students and teachers. In V. Durand-Guerrier, S. Soury-Lavergne, \& F. Arzarello (Eds.) Proceedings of the Sixth Congress of the European Society for Research in Mathematics Education (pp. 2356-2365). Lyon, France.

Watson, A. (2004). Affordances, constraints and attunements in mathematical activity. Research in Mathematics Education, 6, 23-34. 
Watson, A. (2007). The nature of participation afforded by tasks, questions and prompts in mathematics classrooms. Research in Mathematics Education, 9, 111-126.

Watson, A., \& Mason, J. (2005). Mathematics as a Constructive Activity: Learners Generating Examples. Mahwah, NJ: Lawrence Erlbaum Associates.

Watson, A., \& Mason, J. (2007). Taken-as-shared: a review of common assumptions about mathematical tasks in teacher education. Journal of Mathematics Teacher Education, 10, 205-215.

Zaslavsky, O. (2008). Meeting the challenges of mathematics teacher education through design and use of tasks that facilitate teacher learning. In B. Jaworski \& T. Wood (Eds.), The Mathematics Teacher Education as a Developing Professional (pp. 93-114). Rotterdam: Sense Publishers.Campbell, E. (2006). Ethical knowledge in teaching: A moral imperative. Education Canada, 46(4), 32-35. 